\title{
Biosorption of diesel and lubricating oil on algal biomass
}

\author{
Praveen Kumar Mishra $\cdot$ Suparna Mukherji
}

Received: 11 December 2011/Accepted: 7 March 2012/Published online: 25 March 2012

(C) The Author(s) 2012. This article is published with open access at Springerlink.com

\begin{abstract}
Algae are widely used as biosorbent for the sorption of heavy metals, however sorption of oil on algae has not been explored. Algae in marine and fresh water environment may affect the fate and transport of spilled oil. Sorption of diesel and lubricating oil was studied using dead biomass of Spirulina sp. and Scenedesmus abundans. The rate and extent of sorption was studied in well mixed batch systems containing oil (0.1-2\%, v/v) and biomass $(0.1 \%)$ suspended in water. Sorption of diesel on Spirulina sp. was instantaneous. Rate limited sorption on algal biomass could be explained by the pseudo-second order model and equilibrium was established within 12 days. The Freundlich and Langmuir model could provide adequate fit for diesel sorption on algae but not for lubricating oil. A three parameter model, the Sips model, provided good fit for all the experimentally generated isotherms and yielded maximum sorption capacity of diesel and lubricating oil in the range of $12-14 \mathrm{~g} / \mathrm{g}$. Oil sorption on algae was comparable to other spill clean-up sorbents. Algae can be used for development of low cost sorbents and can facilitate removal of oil from contaminated water. Sorption is affected both by the type of oil and type of algae. This is the first study illustrating that the additives present in lubricating oil not only reduces the sorption rate but also alters sorption equilibrium such that two-parameter isotherms are inadequate.
\end{abstract}

Electronic supplementary material The online version of this article (doi:10.1007/s13205-012-0056-6) contains supplementary material, which is available to authorized users.

P. K. Mishra · S. Mukherji $(\square)$

Centre for Environmental Science and Engineering (CESE),

Indian Institute of Technology (Bombay), Powai,

Mumbai 400076, India

e-mail: mitras@iitb.ac.in
Keywords Sorption isotherms - Sorption capacity · Sorption rate $\cdot$ Hydrocarbon sorption - Cyanobacteria

\section{Introduction}

Oil spills in the aquatic environment is a major environmental hazard and is reported to cause death of sea birds and other aquatic animals. Although spilled oil is primarily removed by controlled burning, dredging, dispersants, oil booms, skimmers and vacuum techniques (Ghannam and Chaalal 2003), sorption on spill clean-up sorbents is often used for containing oil spills. The spill clean-up sorbents have oil sorption capacity ranging from 0.26 to $86 \mathrm{~g} / \mathrm{g}$, depending on the type of sorbent and on the type and initial concentration of oil ( $C_{\mathrm{o}}$, Moazed and Viraraghavan 2005). Organic sorbents derived from plants are often preferred over inorganic and synthetic sorbents since they are more readily biodegradable and typically have higher oil sorption capacity. The diesel sorption capacity of spill sorb and peat sorb containing 54 and $90 \%$ organic matter was 1.18 and $4.35 \mathrm{~g} / \mathrm{g}$, respectively, for $C_{\mathrm{o}}$ range of $2-50 \mathrm{~g} / \mathrm{L}$ (Biswas et al. 2005). Crude oil sorption on saw dust and oleic acid grafted sawdust was in the range of $4.23-6.4 \mathrm{~g} / \mathrm{g}$ for $C_{\mathrm{o}}$ range of 2-14.5 g/L (Banerjee et al. 2006). Most studies with spill clean-up sorbents have not depicted variation in oil loading $(\mathrm{g} / \mathrm{g})$ with variation in aqueous phase concentration $(\mathrm{g} / \mathrm{L})$ at equilibrium. Use of such sorption isotherms can facilitate effective comparison across sorbents by fitting the experimentally generated isotherms with isotherm models.

Numerous studies have reported good sorption of contaminants on biomass derived from algae, fungi and bacteria. Biosorption is reported for a wide range of pollutants, i.e., heavy metals, phenolic compounds, dyes, and aromatic 
hydrocarbons (Aksu and Tezer 2005; Beolchini et al. 2006; Lei et al., 2007). It is widely recognized that algae can serve as low cost sorbents that can be applied for removal of various toxic heavy metal ions from aqueous solution containing less than $100 \mathrm{mg} / \mathrm{L}$ of heavy metal ions. Large amounts of algal biomass can be generated economically in open ponds and ditches or in large scale engineered bioreactors. Algae does not require organic carbon source for growth, hence, they can be cultivated in a cost effective and reliable manner using light. Algae growing phototropically can utilize carbon dioxide from the atmosphere or inorganic carbon present in water $\left(\mathrm{H}_{2} \mathrm{CO}_{3}{ }^{*}, \mathrm{HCO}_{3}{ }^{-}\right.$and $\mathrm{CO}_{3}{ }^{2-}$ ). Some algae, primarily blue-green algae (cyanobacteria) can also grow mixotrophically using both organic and inorganic carbon sources. Cyanobacteria are also known to grow effectively under low nutrient conditions. Thus, a reliable supply of algal biomass can be generated at low cost and there is much scope for utilization of algae as biosorbent due to their high surface area to volume ratio and due to the nature of their cell wall.

Researchers have focused on biosorption of metals on both green algae and cyanobacteria, such as, chromium (VI) sorption on Spirogyra sp. (Gupta et al. 2001); Nostoc muscorum (Gupta and Rastogi 2008) and Oedogonium hatei (Gupta and Rastogi 2009); cadmium sorption on Spirulina (Doshi et al. 2007) and sorption of copper, nickel and chromium (VI) on Scenedesmus obliquus and Synechocystis sp. (Çetinkaya et al. 1999). These studies have evaluated sorption kinetics and sorption equilibrium and have evaluated goodness of fit to various kinetic models (pseudo first order and pseudo second order model) and isotherm models. Both the sorption kinetic models have been widely applied to metal sorption data. In most cases metal sorption on algae is reported to be a fast process ranging from a few minutes to several hours. The Freundlich isotherm and Langmuir isotherm have been reported to provide good fit to metal sorption data derived from batch equilibrium studies. Desorption of sorbed heavy metal ions for promoting reuse of sorbent has also been explored and found to be feasible with proper choice of regenerant. Researchers have also attempted to decipher the sorption mechanism of various metal ions on algal biomass. Sorption has been correlated with the type of functional groups present on the algal cell wall as determined through FTIR studies (Çetinkaya et al. 1999; Doshi et al. 2007; Gupta and Rastogi 2008 and 2009). The contribution of physical sorption is reported to be much lower than that of chemisorption, where the latter primarily occurs through ion exchange in a $\mathrm{pH}$ dependent manner. Chojnacka et al. (2005) revealed that the growth conditions of Spirulina sp. (light intensity and glucose concentration determining, phototrophic, mixotrophic and autotrophic growth) significantly affected the relative abundance of various surface functional groups (carboxyl, phosphate, hydroxyl and amine) which in turn had a significant impact on biosorption of various heavy metal ions. Sorption of $\mathrm{Cr}^{3+}, \mathrm{Cd}^{2+}$ and $\mathrm{Cu}^{2+}$ ions on Spirulina sp. increased as $\mathrm{pH}$ increased due to deprotonation of the surface functional groups and development of negative charge on the surface. Over the pH range 3-9, the carboxyl and phosphate groups had maximum impact on sorption through ion exchange. In contrast, sorption of $\mathrm{Cr}(\mathrm{VI})$ on various algae and cyanobacteria was reported to be maximum in the $\mathrm{pH}$ range $2-3$ since $\mathrm{Cr}(\mathrm{VI})$ exists as negatively charged species, i.e., chromate and dichromate and at higher $\mathrm{pH}$ values sorption is hindered due to electrostatic repulsion (Gupta et al. 2001; Gupta and Rastogi 2008, 2009). Sorption of Cr(VI) on Nostoc muscorum was found to be favored at elevated temperatures. Based on change in Langmuir isotherm parameters with change in temperature, sorption was found to be endothermic and spontaneous. The solution ionic strength is also reported to impact sorption of heavy metal ions on algae (Beolchini et al. 2006).

Although algae has been widely used as biosorbent for the sorption of heavy metals very limited research has been conducted for sorption of organic pollutants on algae. It is widely recognized that most hydrophobic organic compounds (HOCs) tend to bioconcentrate on algae, fish and other aquatic organisms, however, sorption of HOCs on algae has not been quantified as extensively as for heavy metals. Some researchers have reported sorption of organic micropollutants, such as, chlorobenzenes on Anabaena and Scenedesmus and sorption of low concentration of fluoranthene and pyrene on various microalgae (Koelmans et al. 1995; Lei et al. 2007). Sorption of chlorobenzenes was found to be essentially complete within $24 \mathrm{~h}$ and could be represented in terms of linear isotherms, characterized by a single parameter, i.e., organic carbon normalized partition coefficient, $K_{\mathrm{oc}}$. However, various researchers have demonstrated that sorption of HOCs is also nonlinear and needs to be described by two-parameter Langmuir or Freundlich isotherms when a sufficiently large concentration range is considered (Weber and Digiano 1996). Moreover, unlike metal sorption, HOC sorption kinetics is typically slow, with a rapid phase followed by a slow phase, hence it is important to conduct batch sorption studies over sufficiently long time periods or several days in the range of 10-30 days (Huang and Weber 1997). Also, while several HOCs are inherently volatile and are characterized by large Henry's constant yet others, such as high MW polynuclear aromatic hydrocarbons (PAHs), are highly hydrophobic and tend to sorb strongly to glassware. This necessitates the use of controls in sorption experiments with HOCs for estimation of abiotic losses while such controls are rarely incorporated for determining sorption of heavy metals (Lion et al. 1990; Weber and 
Digiano 1996). Oil is composed of a multitude of HOCs existing in a high concentration in a non aqueous phase liquid (NAPL). Algae from marine and fresh water environment may have a special relevance for development of low cost sorbents for removal of oil. Interaction of algae with oil is also likely to affect the fate and transport of spilled oil in the environment and the fate of oil in oily wastewater treatment studies involving algae where significant accumulation of oil may occur on biomass (Chavan and Mukherji 2008). The objective of this study was to determine the rate and extent of sorption of diesel and lubricating oil on dead algal cultures, Spirulina sp. and Scenedesmus abundans. Sorption isotherms were generated by treating oil suspended in water as analogous to dissolved contaminants. The impact of $\mathrm{pH}$, background ionic strength and temperature on biosorption of oil was also determined.

\section{Materials and methods}

Generation and characterization of biosorbent

Spirulina sp., a cyanobacteria and Scenedesmus abundans, a fresh water green algae, were obtained from a culture collection (NCIM 5143 and NCIM 2897, respectively, NCIM, NCL, Pune, India). Algae was cultured in a $3 \mathrm{~L}$ Haffkin flask containing $1.5 \mathrm{~L}$ of NCIM recommended nutrient medium and incubated at $28{ }^{\circ} \mathrm{C}$ under illumination of 1,500 lux provided with an incandescent lamp operated at L:D cycle of 18:6. The biosorbent was harvested by centrifugation, washed thrice, autoclaved, dried, powdered and sieved to obtain particle size less than $0.5 \mathrm{~mm}$. The sorbent was stored in an air tight container in a dry place at room temperature. The autoclaving and drying steps ensured that the algal culture was inactivated, such that removal of oil from the aqueous phase was solely due to biosorption and not due to metabolic activity. The biosorbents were characterized based on BET and Langmuir surface area and pore size based on liquid nitrogen dry sorption method in a BET surface area analyzer (Micromeritics, USA). The $\mathrm{pH}$ at point of zero charge $\left(\mathrm{pH}_{\mathrm{pzc}}\right)$ values were estimated using the $\mathrm{pH}$ drift method (LopezRamon et al. 1999). The functional groups present on the cell wall of algal samples, Spirulina and Scendesmus abundans, were analyzed using FTIR spectroscopy (Vertex 80 FTIR System, Bruker, Germany). A small amount of algal biomass in dry powder form was mixed with $\mathrm{KBr}$ and the mixed powder was pressed to form a pellet. The spectrum (transmission mode) was obtained in the range of $4,000-500 \mathrm{~cm}^{-1}$ at a resolution of $0.2 \mathrm{~cm}^{-1}$ at room temperature.
Batch studies for biosorption of oil

Lubricating oil (IOCL, Bhandup, Mumbai, India) and diesel (petrol station in Bhandup, Mumbai, India) was first artificially weathered in an open container for $48 \mathrm{~h}$. In the kinetic studies a fixed concentration of oil $\left[C_{\mathrm{o}}=0.5 \%(\mathrm{v} /\right.$ v) for Spirulina $s p$. and $1 \%(\mathrm{v} / \mathrm{v})$ for $S$. abundans] and a fixed dose of biomass $(0.1 \%$, w/v $)$ were used. The $\mathrm{pH}$, temperature and concentration of $\mathrm{NaNO}_{3}$ used as background electrolyte were $7,30{ }^{\circ} \mathrm{C}$ and $0.01 \mathrm{M}$, respectively. The kinetic study was performed using multiple completely mixed batch reactors (CMBR, $50 \mathrm{~mL}$ glass serum bottle capped with Teflon lined septa) tumbled end over end at $50 \mathrm{rpm}$. For estimating residual oil in the aqueous phase, the algal biomass was removed by centrifugation $(12,000 \mathrm{rpm}$ for $10 \mathrm{~min})$. Subsequently, oil was determined by gravimetry after extracting oil from the aqueous phase by adding dichloromethane (DCM, 1:1 v/v) and centrifuging at 10,000 rpm for $10 \mathrm{~min}$ (Biswal et al. 2009). Sorbed oil was calculated based on mass balance assuming same abiotic losses for the control and experimental batches. Rate limited sorption of oil on algae was fitted with the pseudo-second order kinetic model (Eq. 1, Ozer et al. 2006).

$\frac{t}{q_{t}}=\frac{1}{k_{2} q_{\mathrm{e}}^{2}}+\frac{t}{q_{\mathrm{e}}}$

where, $q_{\mathrm{t}}$ and $q_{\mathrm{e}}(\mathrm{g} / \mathrm{g})$ is the oil sorbed at time ' $t$ ' (d) and at equilibrium, respectively, and $k_{2}\left[(\mathrm{~g} / \mathrm{g})^{-1} \mathrm{~d}^{-1}\right]$ is the pseudo-second order biosorption rate constant.

Batch isotherm studies under the same conditions were set-up in multiple CMBRs $(50 \mathrm{~mL})$ with $C_{\mathrm{o}}$ ranging from 0.1 to $2 \%(\mathrm{v} / \mathrm{v})$. Duplicate samples were extracted after providing sufficient time for achieving equilibrium. For each $C_{\mathrm{o}}, q_{\mathrm{e}}$ was calculated using Eq. (2) (Paikaray 2006) which accounts for abiotic losses, such as volatilization. $\hat{S}$ is the slope derived from a plot of concentration in the controls at equilibrium $\left(C_{\mathrm{c}}\right)$ versus $C_{\mathrm{o}}$.

$q_{\mathrm{e}}=\frac{\left[C_{\mathrm{o}}-\frac{C_{\mathrm{e}}}{\hat{S}}\right]}{\frac{M}{V}}$

The experimentally generated isotherms ( $q_{\mathrm{e}}$ vs. $C_{\mathrm{e}}$ data, expressed in $\mathrm{g} / \mathrm{g}$ and $\mathrm{g} / \mathrm{L}$, respectively) were fitted using various two-parameter (Langmuir, eqn. 3 and Freundlich, Eq. 4) and three-parameter isotherm models (RedlichPeterson, Eq. 5 and Sips model (Langmuir-Freundlich model), Eq. 6) (Kumar and Porkodi 2006, Ho et al. 2002). The isotherm parameters for each model were determined using nonlinear regression performed using SYSTAT 10.2 by Gauss-Newton method where the best fit parameter estimates were obtained by minimizing the sum of squared residuals. 
$q_{\mathrm{e}}=\frac{Q_{\mathrm{a}}^{\mathrm{o}} b C_{\mathrm{e}}}{1+b C_{\mathrm{e}}}$

$q_{\mathrm{e}}=\mathrm{K}_{\mathrm{F}} C_{\mathrm{e}}^{n}$

$q_{\mathrm{e}}=\frac{A_{\mathrm{RP}} C_{\mathrm{e}}}{1+b_{\mathrm{RP}} C_{\mathrm{e}}^{\mathrm{g}}}$

$q_{\mathrm{e}}=\frac{Q_{m}^{s}\left(k_{s} C_{\mathrm{e}}\right)^{m_{S}}}{1+\left(k_{s} C_{\mathrm{e}}\right)^{m_{S}}}$

where, the parameters, $Q_{\mathrm{a}}^{\mathrm{o}}(\mathrm{g} / \mathrm{g}), \mathrm{K}_{\mathrm{F}}(\mathrm{g} / \mathrm{g}), A_{\mathrm{RP}}(\mathrm{L} / \mathrm{g}), Q_{m}^{s}$ $(\mathrm{g} / \mathrm{g})$ are the terms related to maximum sorption capacity and $b(\mathrm{~L} / \mathrm{g}), n, \mathrm{~b}_{\mathrm{RP}}(\mathrm{L} / \mathrm{g}), k_{s}(\mathrm{~L} / \mathrm{g})$ are the terms related to sorption energetics in the various models. When ' $g$ ' and ' $m_{s}$ ' attains a value of unity in Eqs. 5 and 6, respectively, these expression reduces to the Langmuir isotherm.

The effect of ionic strength (0.01-1 $\mathrm{M} \mathrm{NaNO}$ ), $\mathrm{pH}$ (2-12) and temperature $\left(20-45^{\circ} \mathrm{C}\right)$, on sorption was tested using a fixed initial concentration of oil of $1 \%(\mathrm{v} / \mathrm{v})$ with other conditions remaining same. Sorbed oil at equilibrium was estimated using Eq. 2 using the same $\hat{S}$ values as determined for the equilibrium studies. Abiotic controls were also maintained to determine the variation in abiotic losses with variation in the experimental conditions. All experiments were conducted in duplicate. The error bars represent standard error and were determined based on propagation of errors for derived variables.

\section{Results and discussion}

The yield of dry biomass was 680 and $360 \mathrm{mg} / \mathrm{L}$, respectively for Spirulina sp. and S. abundans at the end of $\log$ growth phase (11 and 21 days, respectively). In a batch culture, the log growth phase signifies the period when there is an exponential increase in cell count and biomass. Subsequently, conditions in the batch culture are no longer conducive for supporting growth at such a rapid rate. End of log growth phase signifies either depletion of nutrients, increase in $\mathrm{pH}$ to levels that inhibit growth, accumulation of toxins or shading effect (dense growth causing hindrance in penetration of light). The biosorbent prepared using Spirulina sp. yielded higher BET and Langmuir surface area (20.95 and $73.94 \mathrm{~m}^{2} / \mathrm{g}$, respectively) compared to the biosorbent prepared with $S$. abundans $\left(1.38\right.$ and $2.08 \mathrm{~m}^{2} / \mathrm{g}$, respectively). These surface area values based on physical sorption of nitrogen gas molecules on the surface of a sorbent by fitting the BET isotherm and Langmuir isotherm to nitrogen sorption data, respectively, are widely used to characterize the surface area of sorbent. The average pore width for Spirulina sp. biosorbent was $73.27(\AA)$ while that for $S$. abundans biosorbent was 366.77 (§). The $\mathrm{pH}_{\mathrm{PZC}}$ was found to be 8.5 for Spirulina sp. and 7.5 for S. abundans. The FTIR spectra for both Spirulina and S. abundans were very similar to that reported by Doshi et al. (2007) for a Spirulina sp. (supplementary material). The identity of functional groups listed in Table 1 was interpreted based on the spectra obtained and analysis of FTIR spectra for alga reported by various researchers (Gupta and Rastogi 2009; Doshi et al. 2007; Stehfest et al. 2005; Çetinkaya et al. 1999).

The controls indicated much lower extraction loss and additional abiotic loss over 16 days for lubricating oil $(<4 \%)$ than for diesel (50-60\%) (Fig. 1). The aqueous concentration profile stabilized after nearly 10-12 days. Diesel sorption on Spirulina sp. was instantaneous (Fig. 1). Rate limited sorption of oil on algae followed the pseudosecond order kinetics (Fig. 2). The faster sorption rates for diesel compared to lubricating oil on S. abundans is indicated by the pseudo-second order rate constant, $k_{2}$, i.e., $0.51 \pm 0.37$ and $0.06 \pm 0.02\left[(\mathrm{~g} / \mathrm{g})^{-1} \mathrm{~d}^{-1}\right]$ for diesel and lubricating oil, respectively. Lubrication oil sorption on Spirulina sp. $\left[k_{2}=0.15 \pm 0.02(\mathrm{~g} / \mathrm{g})^{-1} \mathrm{~d}^{-1}\right]$ was faster

Table 1 Functional Groups based on FTIR spectra of Spirulina and Scendesmus abundans

\begin{tabular}{|c|c|c|}
\hline \multicolumn{2}{|c|}{ Wave number $\left(\mathrm{cm}^{-1}\right)$} & \multirow[t]{2}{*}{ Functional Groups } \\
\hline Spirulina sp. & Scendesmus abundans & \\
\hline 3324 & 3403 & Carboxylic/phenolic $-\mathrm{OH}$ stretching and stretching of $\mathrm{NH}_{2}$ \\
\hline $2958,2925,2855$ & $2951,2926,2855$ & $-\mathrm{CH}$ stretching \\
\hline 1652 & 1652 & $\mathrm{C}=\mathrm{O}$ stretching of amide-I from proteins \\
\hline 1540 & 1541 & $\mathrm{~N}-\mathrm{H}$ stretching of amides from proteins; amide-II band \\
\hline 1456 & 1456 & Asymmetric deformation of $\mathrm{CH}_{3}$ group of proteins \\
\hline 1404 & 1456 & Symmetric deformation of $\mathrm{CH}_{2}$ and $\mathrm{CH}_{3}$ group of protein, stretching of $\mathrm{C}-\mathrm{O}$ bond in $\mathrm{COO}^{-}$ \\
\hline 1243 & 1252 & Stretching of $\mathrm{P}=\mathrm{O}$ in phospholipids and nucleic acids, stretching of $=\mathrm{C}-\mathrm{C}=$ \\
\hline \multirow[t]{2}{*}{1154,1047} & 1067 & $\mathrm{C}-\mathrm{O}-\mathrm{C}$ stretching of polysaccharides \\
\hline & 873 & Plane deformation \\
\hline \multicolumn{3}{|l|}{667} \\
\hline 576 & 586 & Stretching and bending modes of phosphate \\
\hline
\end{tabular}




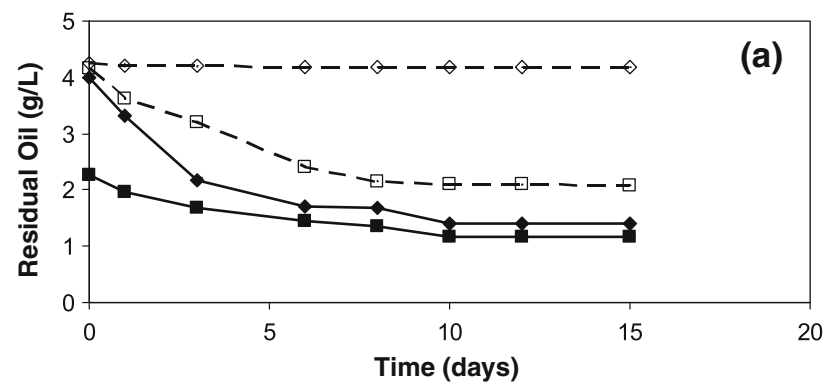

$\longrightarrow \diamond$ Lube_Control $\longrightarrow$ Lube_Expt
$-\square$ Diesel_Control $\rightarrow$ Diesel_Expt
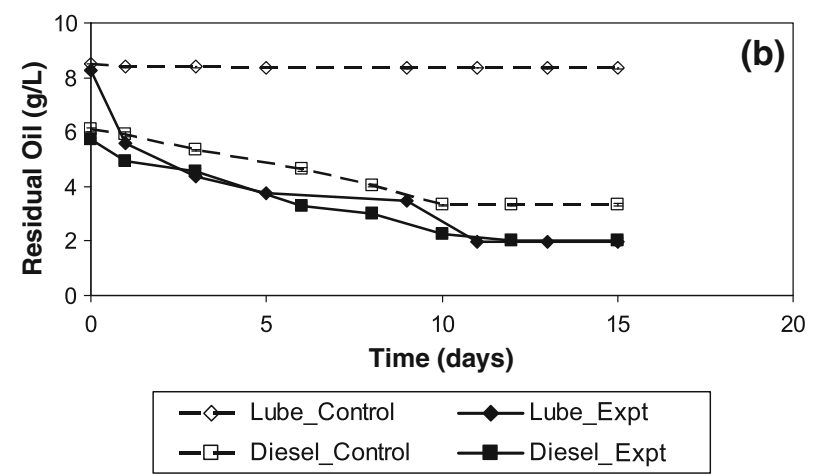

Fig. 1 Sorption of lubricating oil and diesel on (a) Spirulina sp. $\left(C_{\mathrm{o}}=0.5 \%\right)$ and (b) Scendesmus abundans $\left(C_{\mathrm{o}}=1 \%\right)$ over a period of 16 days

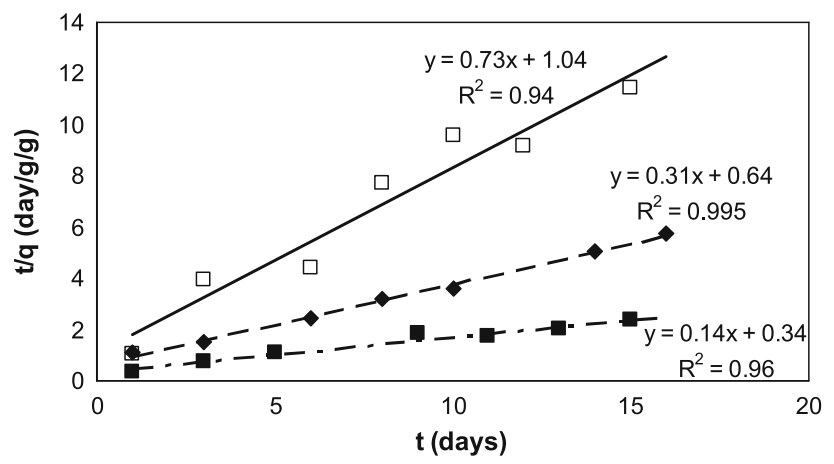

$\diamond$ Spirulina_Lube $\square$ Scenedesmus_Lube $\square$ Scenedesmus_Diesel

Fig. 2 Rate limited sorption of diesel and lubricating oil on algae fitted to pseudo-second order model

than on S. abundans. The kinetic studies for Spirulina sp. was conducted using a lower $C_{\mathrm{o}}(0.5 \%)$ than for $S$. abundans (1\%), thus, at the same $C_{\mathrm{o}}$ differences in $k_{2}$ values for Spirulina sp. and $S$. abundans is expected to be even greater (Aravindhan et al. 2007; Ozer et al. 2006).

The equilibrium studies were set-up for 10 days for all oil-algae combination other than for lubricating oil sorption on $S$. abundans, where 14 days equilibration time was provided. The $q_{\mathrm{e}}$ values reported were obtained using Eq. 2 which corrects for abiotic losses. Some loss of oil is expected due to sorption on glassware and due to volatilization. These losses would occur both in the controls and in the experimental flasks. If uncorrected, they would overestimate sorption on algae. This can cause large errors for volatile oils, such as, diesel. Hence, these losses were estimated based on the controls devoid of algal biosorbent set up with varying initial concentration of oil. If no loss occurs, concentration in the controls after equilibrium $\left(C_{\mathrm{c}}\right)$ would be same as the initial concentration $\left(C_{\mathrm{o}}\right)$ and a plot of $C_{\mathrm{c}}$ versus $C_{\mathrm{o}}$ would be a straight line with slope of unity. However, due to these losses $C_{\mathrm{c}}$ is lower than $C_{\mathrm{o}}$, and it has been reported that $C_{\mathrm{c}}$ and $C_{\mathrm{o}}$ are linearly related, with a slope of $\hat{S}$ (where, $\hat{S} \leq 1$ ), such that $C_{\mathrm{o}}=C_{\mathrm{c}} / \hat{S}$. The residual concentration observed in the experimental flask with sorbent $\left(C_{\mathrm{e}}\right)$ would be equal to $C_{\mathrm{e}} / \hat{S}$ after correction for these losses, and this corrected value needs to be used for estimating sorption on algae. The lower the value of $\hat{S}$, the higher is the abiotic losses due to volatilization and sorption on glassware. An alternative approach for estimating abiotic loss, assumes equal abiotic loss in both the controls and experimental batches for a fixed value of $C_{\mathrm{o}}$, however, this approach would underestimate sorption on the biosorbent.

Good linearity was observed in plots of concentration in controls $\left(C_{\mathrm{c}}\right)$ at equilibrium versus initial concentration $\left(C_{\mathrm{o}}\right)$ with $R^{2}=0.99$ for both lubricating oil and diesel. The slope value $(\hat{S)}$ was 0.96 for lubricating oil and 0.595 for diesel. The significantly lower $\hat{S}$ value for diesel compared to lubricating oil maybe be expected since diesel is composed of $n$-alkanes with lower chain length (nC9-nC24) compared to lubricating oil ( $\mathrm{nC} 14-\mathrm{nC} 40)$ and is thus subjected to greater volatilization losses (Wang and Stout 2007) as was also evident from the kinetic studies. Alternatively, if $q_{\mathrm{e}}$ was estimated assuming equal abiotic losses for control and experimental batches with sorbent corresponding to any $C_{\mathrm{o}}$ value, large errors would have affected the diesel sorption estimates. Comparing the observed $q_{\mathrm{e}}$ values with those reported in the literature for similar range of initial oil concentration, algae was found to have good oil sorption potential comparable to other sorbents, such as, oleic acid grafted sawdust, spill sorb and peat sorb (Banerjee et al. 2006; Biswas et al. 2005). Spirulina sp. was found to be a better sorbent for diesel as compared to the algal consortia predominated by the cyanobacteria, Phormidium (Chavan 2008).

All the isotherms (Fig. 3) depicted significant nonlinearity and were thus fitted using the various two and three parameter isotherm models $(2 \mathrm{a}-\mathrm{d})$ and the parameters were determined by non-linear regression (Table 2). Convergence could not be obtained for Redlich-Peterson model for lubricating oil sorption on both the algal cultures. The various two and three parameter models used yielded $R^{2}$ values $\geq 0.9$ for all other cases. Although $R^{2}$ is widely used 
Fig. 3 Comparison of various model fits to isotherm data for sorption of lubricating oil on (a) Spirulina sp. and

(b) Scenedesmus abundans and for sorption of diesel on

(c) Spirulina sp. and

(d) Scenedesmus abundans
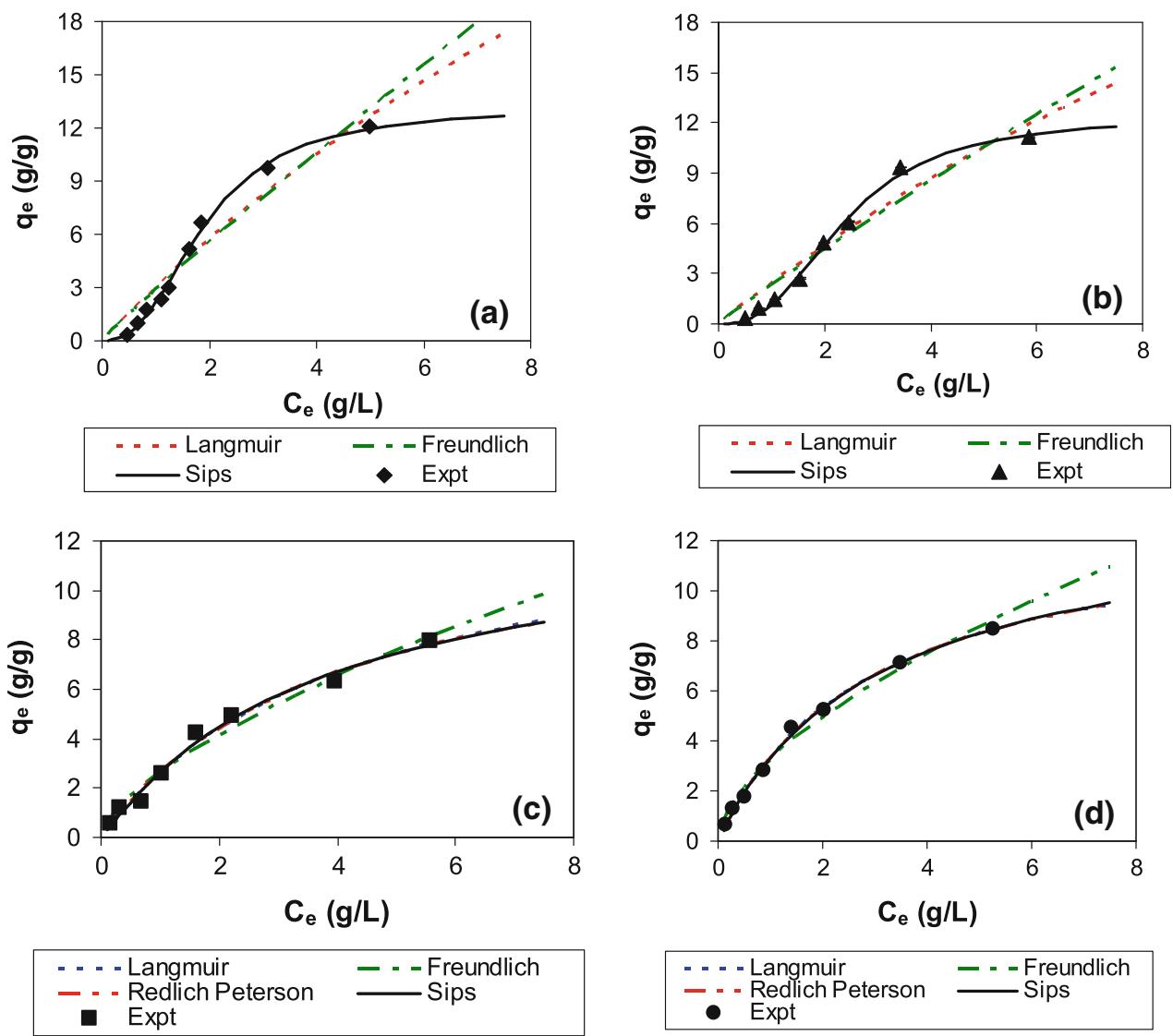

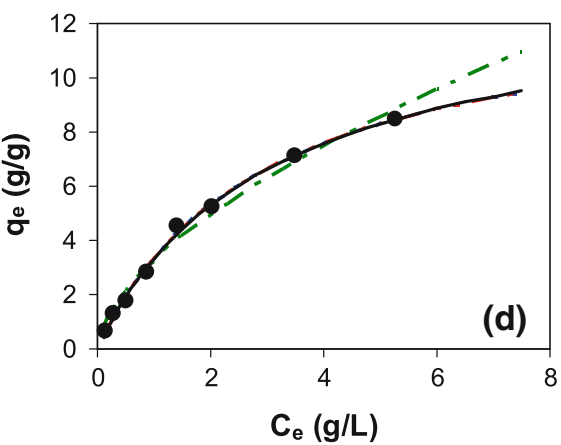

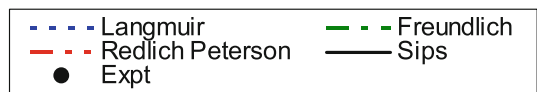

to denote significance of regressions, it does not effectively represent significance of regressions, particularly for nonlinear regression. Even for linear regression, its magnitude is affected by various parameters, such as, the range of independent variable values and the number of data points (Berthouex and Brown, 1994). The high $F$ value for all the regressions, however, clearly indicates that all the models are associated with high significance level (negligible $p$ values $\rightarrow 0$ ). However, for lubricating oil sorption on Spirulina sp. and S. abundans, the parameter estimates for the Langmuir model were associated with large errors and the model fit to data was also inadequate. Although the Freundlich model parameters for lubricating oil sorption on these algal cultures were not associated with such large errors, the model fits to data were found to be unsatisfactory. The Sips model provided the best fit for lubricating oil sorption on these algal cultures. The exponent ' $m_{s}$ ' is reported to account for heterogeneity of the sorbents and interaction between sorbed layers. The ' $m_{s}$ ' value in Sips isotherm for lubricating oil sorption was significantly higher than 1 , indicating the inherent nonlinearity in this isotherm. The Sips isotherm ' $m_{s}$ ' value is typically reported to be $<1$, hence, the observed values for lubricating oil sorption on both the algal cultures were contrary to expectation. Based on Sips model, the maximum sorption capacities for sorption of lubricating oil on Spirulina sp. and $S$. abundans were 13.1 and $12.4 \mathrm{~g} / \mathrm{g}$, respectively. The Langmuir and Freundlich isotherms provided good fits for diesel sorption. The exponent values in the Redlich-Peterson and Sips model were both close to unity for diesel sorption, indicating that these models essentially reduce to the two-parameter Langmuir model. Based on both Langmuir and Sips model, diesel sorption capacity on both the algal cultures were in the range of $12.5-14 \mathrm{~g} / \mathrm{g}$. Thus, the sorption capacity of both diesel and lubricating oil on these algal cultures are comparable. This is also indicated by the Freundlich model term related to sorption capacity $\left(\mathrm{K}_{\mathrm{F}}\right)$ which lies in the range $2.3-3.2(\mathrm{~g} / \mathrm{g})$ for all the cases. The Freundlich exponent ' $n$ ' values were significantly less than unity for diesel sorption isotherms, while they were closer to unity for lubricating oil sorption isotherm. Lower ' $n$ ' values are indicative of more favorable isotherms indicating that $q_{\mathrm{e}}$ remains comparatively higher as $C_{\mathrm{e}}$ reduces (Weber and Digiano 1996). Thus, although sorption capacity for lubricating oil and diesel is comparable for these algal cultures, relatively higher loading on these biosorbents may be expected for diesel at lower $C_{\mathrm{e}}$ values. Although the BET and Langmuir surface area indicated much higher sorption potential for Spirulina sp. compared to $S$. abundans this was not observed for oil sorption. The 
Table 2 Isotherm model parameters based on non-linear regression for sorption of lubricating oil and diesel on Spirulina sp. and Scenedesmus abundans

\begin{tabular}{|c|c|c|c|c|c|c|c|c|c|c|c|}
\hline \multirow[t]{2}{*}{ Isotherm models } & \multirow[t]{2}{*}{ Parameters } & \multicolumn{5}{|c|}{ Spirulina sp. } & \multicolumn{5}{|c|}{ Scenedesmus abundans } \\
\hline & & Mean & SE & $\%$ Error & $F$ & $R^{2}$ & Mean & SE & $\%$ Error & $F$ & $R^{2}$ \\
\hline \multicolumn{12}{|l|}{ Lubricating oil } \\
\hline \multirow[t]{2}{*}{ Langmuir } & $Q_{\mathrm{a}}^{\mathrm{o}}(\mathrm{g} / \mathrm{g})$ & 67 & 63 & 95 & 136 & 0.938 & 58 & 59 & 102 & 110 & 0.933 \\
\hline & $b(\mathrm{~L} / \mathrm{g})$ & 0.05 & 0.05 & 111 & & & 0.04 & 0.05 & 119 & & \\
\hline \multirow[t]{2}{*}{ Freundlich } & $\mathrm{K}_{\mathrm{F}}(\mathrm{g} / \mathrm{g})$ & 2.9 & 0.4 & 15 & 120 & 0.93 & 2.3 & 0.5 & 20 & 96 & 0.924 \\
\hline & $n$ & 0.94 & 0.12 & 12 & & & 0.94 & 0.14 & 15 & & \\
\hline \multirow[t]{3}{*}{ Sips } & $Q_{m}^{S}(\mathrm{~g} / \mathrm{g})$ & 13.1 & 0.6 & 5 & 1,045 & 0.995 & 12.4 & 0.7 & 5 & 870 & 0.995 \\
\hline & $k_{S}(\mathrm{~L} / \mathrm{g})$ & 0.52 & 0.03 & 6 & & & 0.42 & 0.02 & 6 & & \\
\hline & $m_{S}$ & 2.5 & 0.2 & 9 & & & 2.6 & 0.3 & 10 & & \\
\hline \multicolumn{12}{|l|}{ Diesel } \\
\hline \multirow[t]{2}{*}{ Langmuir } & $\underline{Q}_{\mathrm{a}}^{\mathrm{o}}(\mathrm{g} / \mathrm{g})$ & 13.8 & 1.5 & 11 & 716 & 0.987 & 13.3 & 0.6 & 4 & 3,249 & 0.997 \\
\hline & $b(\mathrm{~L} / \mathrm{g})$ & 0.24 & 0.05 & 20 & & & 0.34 & 0.03 & 9 & & \\
\hline \multirow[t]{2}{*}{ Freundlich } & $\mathrm{K}_{\mathrm{F}}(\mathrm{g} / \mathrm{g})$ & 2.6 & 0.2 & 7 & 425 & 0.978 & 3.2 & 0.2 & 5 & 615 & 0.984 \\
\hline & $n$ & 0.65 & 0.05 & 8 & & & 0.60 & 0.04 & 7 & & \\
\hline \multirow[t]{3}{*}{ Redlich-Peterson } & $A_{\mathrm{RP}}(\mathrm{L} / \mathrm{g})$ & 3.2 & 0.8 & 27 & 416 & 0.987 & 4.4 & 0.6 & 13 & 1,805 & 0.997 \\
\hline & $b_{\mathrm{RP}}(\mathrm{L} / \mathrm{g})$ & 0.2 & 0.3 & 128 & & & 0.3 & 0.2 & 47 & & \\
\hline & $g$ & 1.1 & 0.5 & 47 & & & 1.0 & 0.2 & 17 & & \\
\hline \multirow[t]{3}{*}{ Sips } & $Q_{\mathrm{m}}^{\mathrm{s}}(\mathrm{g} / \mathrm{g})$ & 12.7 & 3.8 & 30 & 420 & 0.987 & 13.4 & 1.8 & 13 & 1,805 & 0.997 \\
\hline & $k_{\mathrm{S}}(\mathrm{L} / \mathrm{g})$ & 0.28 & 0.17 & 60 & & & 0.33 & 0.09 & 29 & & \\
\hline & $m_{S}$ & 1.1 & 0.2 & 20 & & & 0.99 & 0.09 & 9 & & \\
\hline
\end{tabular}

$C_{\mathrm{e}}$ is expressed in $\mathrm{g} / \mathrm{L}, q_{\mathrm{e}}$ is expressed in $\mathrm{g} / \mathrm{L}$, and the exponent values in Freundlich, Redlich Peterson and Sips model are dimensionless Convergence could not be obtained for Redlich Peterson model fit to the data for lubricating oil sorption on both the algal cultures

BET and Langmuir surface area values were based on sorption of nitrogen gas and thus cannot adequately represent the surface area on the sorbent that is accessible for components in oil. Oil sorption is expected to be partly due to absorption/partitioning on organic matter and partly due to adsorption on the surface. Sorption of oil may thus be affected more by the organic carbon content (which is expected to be comparable for both the algal cultures) than by surface area of the sorbent. Moreover, the nature and type of functional groups on the sorbent surface may play an important role in oil sorption (Lei et al. 2007). The functional groups on the surface of both the algal cultures were very similar as revealed through the FTIR studies. Thus, comparable oil sorption capacities on both the cultures may be expected.

Effect of various environmental parameters such as ionic strength, $\mathrm{pH}$ and temperature is illustrated in Fig. 4ac. Since $\hat{S}$ was assumed to be unaffected by ionic strength, $\mathrm{pH}$ and temperature the goodness of this assumption was verified by observing variation in $C_{\mathrm{c}}$ with ionic strength, $\mathrm{pH}$ and temperature (supplementary material). While $\mathrm{pH}$ and ionic strength had no effect on $C_{\mathrm{c}}$, increasing temperature had a distinct declining trend which may cause some error in estimation of $q_{\mathrm{e}}$. In general, maximum sorption was attained at low ionic strength, at neutral $\mathrm{pH}$ and at $30-35^{\circ} \mathrm{C}$. The expected trend for dissolved organic solute, i.e., increase in sorption with increase in ionic strength (Chung et al. 2007) was not observed for oil sorption on algae. The trend in $\mathrm{q}_{\mathrm{e}}$ variation with ionic strength was significantly affected by the type of algae. Sorption of both lubricating oil and diesel on Spirulina sp. was highest at the lowest ionic strength (background electrolyte, $\mathrm{NaNO}_{3}$, concentration of $0.01 \mathrm{M}$ ), decreased up to $\mathrm{NaNO}_{3}$ concentration of $0.1 \mathrm{M}$, increased significantly at $0.5 \mathrm{M}$ and subsequently decreased again as $\mathrm{NaNO}_{3}$ concentration was increased to $1 \mathrm{M}$. Sorption of lubricating oil and diesel on $S$. abundans continuously decreased up to $0.5 \mathrm{M}$ and $0.1 \mathrm{M} \mathrm{NaNO}_{3}$, respectively, and subsequently remained invariant as $\mathrm{NaNO}_{3}$ concentration was increased up to $1 \mathrm{M}$.

The $\mathrm{pH}$ dependence was lower for sorption of diesel than for sorption of lubricating oil on both algae. Sorption of oil on algae may be partly due to absorption/partitioning of oil on to organic matter and partly due to adsorption on to the surface of algae due to specific interactions. Absorption/partitioning of HOCs is expected to be a faster phenomenon compared to adsorption and while absorption can be explained by linear isotherms, adsorption is manifested in terms of nonlinear sorption isotherms (Weber and Digiano 1996). It is difficult to determine the relative contribution of the two processes for complex sorbates, 
Fig. 4 Effect of various parameters for sorption on algae (a) ionic strength, (b) $\mathrm{pH}$, (c) temperature
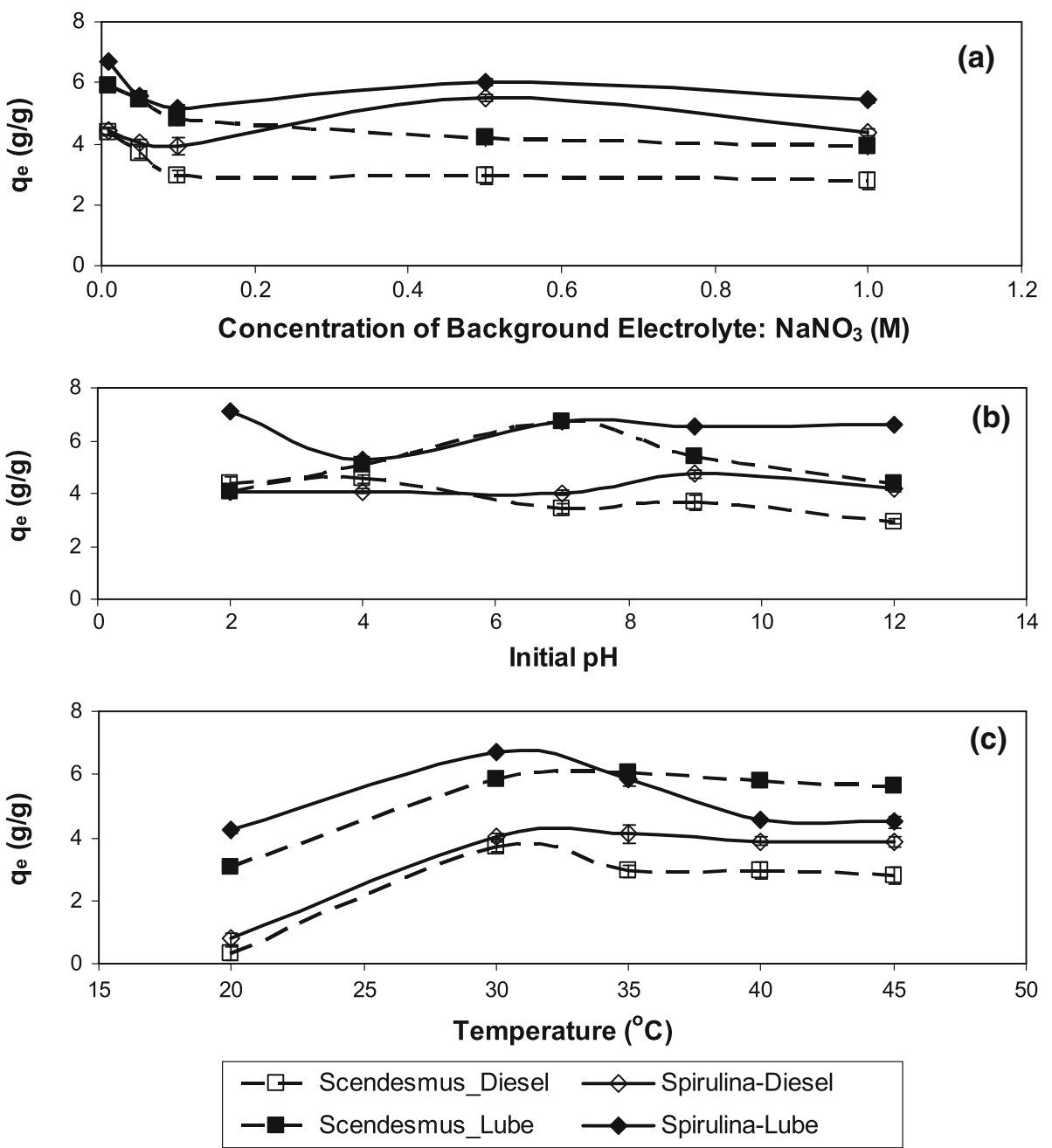

such as, diesel and lubricating oil. While the impact of $\mathrm{pH}$ on absorption/partitioning may be negligible, $\mathrm{pH}$ may have a strong influence on adsorption. For example, sorption of heavy metals occurs primarily by adsorption and is strongly influenced by the system $\mathrm{pH}$. At any $\mathrm{pH}$, the surface functional groups attain positive or negative charge depending on their $\mathrm{pK}_{\mathrm{a}}$ values. It has been shown that for heavy metal ions that carry a positive charge, sorption increases as $\mathrm{pH}$ increases over the range 2-6 due to increasing deprotonation of surface functional groups (carboxyl and phosphate groups) and development of negative charge on the surface that promotes ion exchange (Chojnacka et al. 2005). In contrast, for $\mathrm{Cr}$ (VI) that exist as a negatively charged species in aqueous solution, sorption decreases as $\mathrm{pH}$ increases over the range 2-6 due to development of negative charge on the surface that hinders chemisorption through ion exchange with surface functional groups. While sorption of oil is unlikely to occur through ion exchange, the spontaneous protonation and deprotonation of surface functional groups may still influence sorption. Hydrocarbon and oil droplets often carry negative charge in aqueous solution (Djerdjev and Beattie 2008). Thus, negative charge on the biosorbent surface at $\mathrm{pH}$ exceeding $\mathrm{pH}_{\mathrm{PzC}}$ may hinder sorption through electrostatic repulsion and this may have an adverse impact on both absorption and adsorption processes. Moreover, $\mathrm{pH}$ can also impacts the surface charge on sorbates (Davis et al. 2003, Ozer et al. 2006). The surface charge on algae would depend on the protonation-deprotonation status of the various functional groups, i.e., carboxyl, hydroxyl, amides and amines, present on algae as depicted in Table 1. At a $\mathrm{pH}$ equal to $\mathrm{pH}_{\mathrm{PZC}}$ the surface would be uncharged and sorption is expected to be maximum at this $\mathrm{pH}$. In general, $q_{\mathrm{e}}$ was high at neutral $\mathrm{pH}$ close to $\mathrm{pH}_{\mathrm{PZC}}$, however, the high $q_{\mathrm{e}}$ value for lubricating oil on Spirulina sp. (Fig. 4b) at pH 2 cannot be explained on this basis. Diesel sorption on both the sorbents depicted less variation with $\mathrm{pH}$ changes compared to lubricating oil sorption. It is possible that the contribution of absorption/partitioning is more for sorption of diesel on algae compared to sorption of lubricating oil on algae as also evident from the significantly greater nonlinearity associated with lubricating 
oil isotherms. The additives added to lubricating oil possibly affect its sorption behavior.

At $20^{\circ} \mathrm{C}$, diesel sorption on both algae was remarkably reduced. In all cases sorption was highest at $30-35{ }^{\circ} \mathrm{C}$. Subsequently, sorption remained relatively constant with increase in temperature, except for lubricating oil sorption on Spirulina sp. where a sharp drop in sorption was observed as the temperature increased from 30 to $40{ }^{\circ} \mathrm{C}$. Decrease in sorption with increase in temperature is indicative of an exothermic sorption process. Increase in temperature from 20 to $30{ }^{\circ} \mathrm{C}$ may have increased the diffusivity of oil and thus overcome mass transfer rate limitation (Ozer et al. 2006). Thus, low sorption at $20{ }^{\circ} \mathrm{C}$ may be attributed to rate limited mass transfer.

The differences in sorption observed for Spirulina sp. and $S$. abundans is possibly due to differences in their cell wall structure, surface properties and differences in the arrangement of cells of the prokaryotic and eukaryotic organism, respectively (Davis et al. 2003; Lei et al. 2007). The cyanobacteria, Spirulina, is a prokaryotic organism consisting of spiral shaped chains of cells (trichomes) enclosed in a thin sheath. It is reported to have a layered cell wall structure where a peptidoglycan layer is flanked by fibrillar layers on both sides. The eukaryote, Scenedesmus abundans, is a green algae, also having a layered cell wall with 2-3 distinct layers containing cellulose and pectin. It grows in colonies comprising of four cells attached side by side and has tiny projections. The difference in sorption kinetics and sorption equilibrium observed between the two types of oil is related to the differences in the nature of their constituents. Diesel is primarily composed of aliphatic hydrocarbons from C9 to C24. Lubricating oil consists of about $90 \%$ mineral oil and $10 \%$ additives that contribute to reduced friction, increased viscosity and corrosion resistance. Lubricating oil is also reported to contain naphthenic acids in addition to hydrocarbons. The GC chromatograms of lubricating oil is characterized by a large unresolved complex mixture (UCM) hump while that of diesel shows an abundance of distinct peaks with a very small UCM hump (Mohanty and Mukherji 2008; Biswal et al. 2009).

\section{Conclusions}

Although algal cultures have been extensively used as sorbent for heavy metals, this is the first study reporting biosorption of oil on algae. Significant sorption of oil on algae, comparable to that of other oil spill clean-up sorbents is illustrated. Sorption rate of lubricating oil is found to be significantly lower than for diesel due to the additives present in lubricating oil. Two parameter isotherms, such as, Langmuir and Freundlich isotherms, that have been used for some oil sorption studies were adequate for diesel but not for lubricating oil. Algae can be used for development of low cost sorbents for removal of oil and can affect the fate and transport of spilled oil.

Acknowledgments The authors would like to thank Prof. Jayesh Bellare, Department of Chemical Engineering, IIT Bombay for providing facilities for BET surface area measurement and Centre for Research in Nanotechnology and Science-Sophisticated Analytical Instrumental Centre (CRNTS-SAIF) at IIT Bombay for FTIR analysis of algal samples.

\section{Conflict of interest There is no conflict of interest}

Open Access This article is distributed under the terms of the Creative Commons Attribution License which permits any use, distribution, and reproduction in any medium, provided the original author(s) and the source are credited.

\section{References}

Aksu Z, Tezer S (2005) Biosorption of reactive dyes on the green alga Chlorella vulgaris. Process Biochem 40:1347-1361

Aravindhan R, Rao JR, Nair BN (2007) Removal of basic yellow dye from aqueous solution by sorption on green alga Caulerpa scalpelliformis. J Hazard Mater 142:68-76

Banerjee SS, Joshi MV, Jayaram RV (2006) Treatment of oil spill by sorption technique using fatty acid grafted sawdust. Chemosphere 64:1026-1031

Beolchini F, Pagnanelli F, Toro L, Veglio F (2006) Ionic strength effect on copper biosorption by Sphaelotilus natans: equilibrium study and dynamic modeling in membrane reactor. Water Res 40:144-152

Berthouex PM, Brown LC (1994) Statistics for environmental engineers. Lewis Publishers, CRC Press, Boca Raton

Biswal BK, Tiwari SN, Mukherji S (2009) Biodegradation of oil in oily sludges from steel mills. Bioresource Technol 100:1700-1703

Biswas S, Chaudhari SK, Mukherji S (2005) Microbial uptake of diesel oil sorbed on soil and oil spill clean-up sorbents. J Chem Technol Biotechnol 80:587-593

Çetinkaya DG, Aksu Z, Öztürk A, Kutsal T (1999) A comparative study on heavy metal biosorption characteristics of some algae. Process Biochem 34:885-892

Chavan A (2008) Algal-Bacterial System for the Treatment of Petroleum Hydrocarbon Containing Wastewater in Rotating Biological Contactor Ph.D. Thesis, IIT Bombay, India

Chavan A, Mukherji S (2008) Treatment of hydrocarbon-rich wastewater using oil degrading bacteria and phototrophic microorganisms in rotating biological contactor: effect of $\mathrm{N}: \mathrm{P}$ ratio. J Hazard Mater 154:63-72

Chojnacka K, Chojnacki A, Górecka H (2005) Biosorption of $\mathrm{Cr}^{3+}$, $\mathrm{Cd}^{2+}$ and $\mathrm{Cu}^{2+}$ ions by blue-green algae Spirulina sp.: kinetics, equilibrium and the mechanism of the process. Chemosphere 59:75-84

Chung MK, Tsui MTK, Cheung KC, Tam NFY, Wong MH (2007) Removal of aqueous phenanthrene by brown seaweed Sargassum hemiphyllum: sorption-kinetic and equilibrium studies. Sep Purif Technol 54:355-362

Davis TA, Volesky B, Mucci A (2003) A review of the biochemistry of heavy metal biosoprtion by brown algae. Water Res $37: 4311-4330$

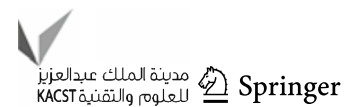


Djerdjev AM, Beattie JK (2008) Electroacoustic and ultrasonic attenuation measurements of droplet size and $\zeta$-potential of alkane-in-water emulsions: effects of oil solubility and composition. Phys Chem 10:4843-4852

Doshi H, Ray A, Kothari IL (2007) Biosorption of cadmium by live and dead Spirulina: IR spectroscopic, kinetics, and SEM studies. Curr Microbiol 54:213-218

Ghannam MT, Chaalal O (2003) Oil spill cleanup using vacuum technique. Fuel 82:789-797

Gupta VK, Rastogi A (2008) Sorption and desorption studies of chromium(VI) from nonviable cyanobacterium Nostoc muscorum biomass. J Hazard Mater 154:347-354

Gupta VK, Rastogi A (2009) Biosorption of hexavalent chromium by raw and acid-treated green alga Oedogonium hatei from aqueous solutions. J Hazard Mater 163:396-402

Gupta VK, Shrivastava AK, Jain N (2001) Biosorption of chromium(VI) from aqueous solutions by green algae Spirogyra species. Water Res 35:4079-4085

Ho YS, Porter JF, Mckay G (2002) Equilibrium isotherm studies for the sorption of divalent metal ions on to peat: copper, nickel and lead single component systems. Water Air Soil Poll 141:1-33

Huang W, Weber WJ Jr (1997) A distributed reactivity model for sorption by soils and sediments. 10. Relationships between desorption, hysteresis, and the chemical characteristics of organic domains. Environ Sci Technol 31:2562-2569

Koelmans A, Anzion SF, Lijklema L (1995) Dynamics of organic micropollutant biosorption to cyanobacteria and detritus. Environ Sci Technol 29:933-940

Kumar VK, Porkodi K (2006) Relation between some two- and threeparameter isotherm models for the sorption of methylene blue onto lemon peel. J Hazard Mater 138:633-635
Lei AP, Hu ZL, Wong YS, Tam NFY (2007) Removal of fluoranthene and pyrene by different microalgal species. Bioresource Technol 98:273-280

Lion LW, Stauffer TB, MacIntyre WG (1990) Sorption of hydrophobic compounds on aquifer materials: analysis methods and the effects of organic carbon. J Contam Hydrol 5:215-234

Lopez-Ramon MV, Stoeckli F, Moreno-Castilla C, Carrasco-Marin F (1999) On the characterization of acidic and basic surface sites on carbons by various techniques. Carbon 37:1215-1221

Moazed H, Viraraghavan T (2005) Removal of oil from water by bentonite organoclay. Pract Period Hazard Toxic Radioact Waste Manage 9:130-134

Mohanty G, Mukherji S (2008) Biodegradation rate of diesel range $n$ alkanes by bacterial cultures Exiguobacterium aurantiacum and Burkholderia cepacia. Int Biodeter Biodegrad 61:240-250

Ozer A, Akkaya G, Turabik M (2006) Biosorption of Acid Blue 290 (AB 290) and Acid Blue 324 (AB 324) dyes on Spirogyra rhizopus. J Hazard Mater B135:355-364

Paikaray S (2006) Sedimentology of Vindhyan Shales and their Sorption Potential for Heavy Metals and Organic Pollutants $\mathrm{Ph} . \mathrm{D}$. Thesis, IIT Bombay, India

Stehfest K, Toepel J, Wilhelm C (2005) The application of microFTIR spectroscopy to analyze nutrient stress-related changes in biomass composition of phytoplankton algae. Plant Physiol Biochem 43:717-726

Wang Z, Stout SA (2007) Oil spill environmental forensicsfingerprinting and source identification. Academic Press, Amsterdam

Weber WJ Jr, Digiano F (1996) Process dynamics in environmental systems. Wiley Interscience, New Jersey 